\title{
Sciendo
}

\section{Content Analysis of Gossip at Different Levels of a Hospital}

\author{
Maryam BABAEI AGHBOLAGH ${ }^{1}$, Farzad Sattari ARDABILI, ${ }^{1, *}$ \\ Elena VOITENKO²
}

\author{
${ }^{1}$ Department of Management, Ardabil Branch, Islamic Azad University, Ardabil, Iran, f.sattari@iauardabil.ac.ir (*corre- \\ sponding author) \\ ${ }^{2}$ Department of Psychology, Kyiv National University of Trade and Economics, Kyiv, Ukraine
}

\begin{abstract}
Background: Most societies have a negative attitude toward gossip and managers are concerned about the impact of gossips on the communication in an organizational environment. Our study examined the perception of gossip, and the context of gossip at different levels of a hospital, a case of organization with high communicational relation among staff. Also, the differences between the gossip context within the organizational context and within the social environment have been considered.

Methodology: Semi-structured interviews were conducted with 27 informants, 9 in each of three groups: nurses, supervisors and managers of the Hospital. Recorded interviews were analyzed using content analysis, and results for each group of respondents were compared. Finally, the main gossiping issues for each group were categorized. Results: The study revealed that the topics of gossip in a hospital can be divided into eight main categories, and 34 sub-categories all identifiable by special topics. These main topics included confidentiality issues, merits, financial status/standing, personal characteristics, position, communications, biography, and job conditions. In terms of organizational gossip, a person's merit in the workplace and financial standing were of particular interest to the participants of this study. Also, the gossip topics at different levels among nurses, administrators, and managers had significant differences.

Conclusion: Managers should acknowledge different gossip contents among people at different organizational levels, and that employees do not have the same motives for communication at different organizational levels. Additionally, the distances between contents in the Tendency to Gossip Questionnaire and categories in the organizational environment need more studies, to explore precedents and outputs. Managers may use these findings to facilitate organizational change and communication.
\end{abstract}

Keywords: Gossip in organizations, Construct of gossip, Content analysis, Informal communication

\section{Introduction}

Gossip is an "evaluative informal discussion about the social environment member who is absent" (Dores Cruz, Nieper, Testori, Martinescu, \& Beersma, 2021; Lee \& Workman, 2013). People are, with a significant frequency, volunteers of gossiping (Beersma \& Van Kleef, 2011) and gossiping is effective on pro-social behavior and on the intention to volunteer (Eckhaus \& Ben-Hador, 2020).
However, most societies have a negative attitude toward gossip, but on the other hand, view gossip as a form of verbal communication to praise or denigrate people (Ceylan \& Çetinkaya, 2020), or as a player in employees task-related behavior (Tan, Yam, Zhang, \& Brown, 2021). From the perspective of organizational managers, because gossip can cause problems in the organization, managers should be concerned with the content of gossip in the organizational environment (Wittek, Hangyi, Van Duijn, \& Carroll, 2000). In fact, a one-dimensional (negative) view of peo-

Received: 2nd February 2021; revised: 21th September 2021; accepted: 6th October 2021 
ple on gossip has led managers to have the opinion that it should be eradicated from organizations, claiming that employees "steal" money from the organization by getting involved in gossiping, not working hard, and wasting their time (Noon \& Delbridge, 1993). However, some studies indicate that gossip can play both positive and negative roles in organizations and have various effects on organizations' management and staffing (Chang \& Kuo, 2020; Ellwardt, Labianca, \& Wittek, 2012). In general, researchers remain ambivalent about gossiping with some claiming it can positively help managers make better decisions, yet others considering it to be detrimental (Clegg \& van Iterson, 2009). Gossip is naturally consistent with informal organizational networks and informal structures of organizations have a mutual relationship with their formal structures so that similar functions might be expected for gossiping in both networks (Mills, 2010).

Researchers have categorized gossip into two types: positive and negative (Grosser, Kidwell, \& Labianca, 2012), with each type having different functions and results. In a study in an organizational environment, Georganta, Panagopoulou, and Montgomery (2014) found that negative gossip in a hospital is positively correlated with emotional exhaustion, depersonalization, and suboptimal care, and is negatively correlated with patient safety culture and job commitment. Another study showed that gossips turned out to be an important determinant regarding women's motivation for and ability to participate in health-promoting activities. Moreover, gossip was identified as a factor strongly undermining their health and sense of wellbeing (Aambø, 2017) and that, employees who are exposed to gossip feel sad and angry and distrust the organization in which they are working (Şantaş, Uğurluoğlu, Özer, \& Demir, 2018).

A review of a significant number of studies shows that people participate in positive and negative gossiping for many reasons and may have different aims (Foster, 2004; Liff \& Wikström, 2021; Michelson, Van Iterson, \& Waddington, 2010). In this regard, Foster (2004) argues that in a social structure, people participate in gossiping for four reasons: information, entertainment, influence, and friendship. Furthermore, studies indicate that employees' level of neuroticism moderates the positive effect of the workplace, negative gossip, and work-family conflict. It also moderates the mediating effect of workplace negative gossip on employees' work-family conflict by psychological distress (Liu, Wu, Yang, \& Jia, 2020). However, the researchers found that people with higher perceived insider status in the organization are more likely to be interested in positive gossip because of their more desirable treatment and the motivations offered by their organization and supervisor. Hence, in order to foster positive gossip and detract negative gossip in an organization, it is necessary to make people feel as though they are insiders and depend on their organization (Kim, Moon, \& Shin, 2019).
Additionally, recent studies show that a tendency to gossip through different levels may result in different outcomes. For example, positive gossip among managers affects commitment and recognition in subordinates (Chang \& Kuo, 2020) which are clues to reconsidering gossiping in organizations at different organizational levels and in a top-down manner.

To or best knowledge, the only available model in the field of gossip content is the study by Nevo, Nevo, and Derech-Zehavi (1993) who defined gossip according to its four aspects of physical appearance, social information, achievement, and sublimation. Their proposed model Tendency to Gossip Questionnaire (TGQ) was based on the study conducted on students in a learning environment and has adopted a social perspective.

Some factors cause organizational environments to differ from each other, including purposes, strategies, different operational, management levels, and the nature of the job a person has. Some official rules and regulations in organizations make these differences more pronounced. A simple example of such laws and regulations is the uniforms worn by employees of an organization, which makes their clothes more unified and reduces variety (Lee \& Workman, 2013), consequently reducing the curiosity of people, causing them not to use gossip on clothing as a means of comparison. Physical appearance in TGQ model is the first priority and has the most prominence and frequency; people speak and show curiosity about the changes and diversity of dresses, appearances, and behaviors.

In addition, gossip has its roots in interaction and communication, and its amount may vary at different organizational levels. Subordinates may use negative gossip to put the supervision under motional and cognitional threats (Ye, He, \& Sun, 2021). Moreover, organizational factors that can contribute to gossip may have different effects at various levels. For instance, nurses, as frontline employees of the hospital, work under stressful conditions and are more likely to spread gossip. Gossips among nurses can improve their social ties regardless of the generated positive or negative gossip (Thomas \& Rozell, 2007). The findings revealed that gossip helps nurses express their feelings and overcome their difficult and stressful working conditions (Waddington, 2005; Waddington \& Michelson, 2007). The change in speaking topic from working to personal releases employees' minds from the stressful conditions of patients and the hospital and provides them a way of coping with strategy (Georganta et al., 2014).

Considering the role of gossip in the organization, its role in hospitals is valuable to study in hospitals where communication is very important in the healthcare system performance and nurses' job outcomes (Ardabili, 2020). At a first glance, the outcomes of the hospitals have been affected positively by information technology (Arfara, Tsivos, Samanta, \& Kyriazopoulos, 2017) and gossip is the way to boost the ability of informal communication 
and transference of information. In the wake of such influence, it stands to reason that the causes and consequences of gossip may be different in organizational environments compared to non-organizational ones. To determine whether such differences exist, the basic structures of organizational gossip should be identified to facilitate the distinction between social and organizational gossip.

The present study aimed to investigate the contents of the organizational gossip and answer the following questions:

- Which types of gossip exist in an organizational environment?

- What do employees say about others?

- Do these topics have distinct constructs and groupings?

- Does the gossip content change according to the organizational levels?

\section{Literature Review}

The role of gossip in organizations has been considered recently and gossip is of critical importance in management, due to its role in reinforcing social bonds and formal work structures (Liff \& Wikström, 2021) and also because of its effects on informal communication. However, many researchers have analyzed the role of organizational gossip in a limited form (Hallett, Harger, \& Eder, 2009), paying little attention to its positive impact on organizations (Eckhaus \& Ben-Hador, 2020) and different organizational groups in achieving organizational goals. Fan and Dawson (2021) explained that social interactions are often viewed as activities beyond the edges of organizational life so less value has been attributed to gossip in organizations by managers, even though gossip is "at the core of human social relationships" (Michelson et al., 2010).

Enhancing employees' performance levels in healthcare systems, especially nurses, is important for both health institutions and patients who are in direct contact with patients (Durmuş, Kirilmaz, \& Şahin, 2020). Covid-19 pandemic showed that the healthcare professionals' job performances and effective services are important in the face of busy, long, and stressful working conditions. But high stress in the work environment and increasing pressure and concern, affect the amount of gossip shared (Bulduk, Özel, \& Dinçer, 2016).

\subsection{Gossip, Culture, and Organizations}

Gossip has been identified as a tool that helps people to know and understand their social environment better. As social interaction, some people do gossip for various reasons such as group protection, self-interest, or evolutionary needs (Bechtoldt, Beersma, \& Dijkstra, 2020). But there is no evidence for specific motives for gossiping in an organizational context. In the organizational view, managers try to enhance productivity through developing the quality of work-life, well-being, and motivating employees (Abdi, Chaib, \& Verzea, 2020) which may be mediated or affected by gossiping in various ways, e.g., through positive gossip about mangers to increase commitment to the managers (Chang \& Kuo, 2020). In instances where information transfer cannot be done through official channels, gossip can help people understand the environmental conditions better, and cause environmental recognition in organizations through which people gain the ability to compete for organizational bonuses and promotions (Kniffin \& Wilson, 2010). From the perspective of cultural learning, gossip can teach people how to be successful in an environment and how to learn from others' mistakes (Grosser, Lopez-Kidwell, \& Labianca, 2010). Moreover, when assessing their performance and determining ways to improve it, employees can be assisted by gossip to collect information and compare themselves with others (Waddington \& Michelson, 2007).

The exchange of information through gossip can also reduce stress and anxiety in situations, such as organizational changes, by implementing group norms and strengthening social bonds in the organization (Kniffin \& Wilson, 2005). People motivated to protect the group may spread negative gossip on members whose behaviors violate the norms of the group and spread positive gossip on behaviors that conform to group norms and strengthen them (Ellwardt et al., 2012), because as defined earlier, gossip is an informal discussion in the social environment on an absent member (Babaei Aghbolagh \& Ardabili, 2016; Lee \& Workman, 2013). This gossiping occurs in such a way that people may not show the same reaction to strangers (Beersma \& Van Kleef, 2012). Thus, this process can be helpful in educating members on organizational culture (Michelson et al., 2010). Accordingly, it is argued that gossip, through cultural education and social comparison by which people take actions to improve their position and performance, can lead to improvements in organizational performance.

\subsection{Gossip and Organizational Changes}

Gossip is also used to express concerns and feelings on threats to an organization's internal policies and may cause some resistance to the implementation of change programs (Ybema, 2004). Based on this viewpoint, gossip can act as a process through which administrative privileges are put to challenge and questioned and the powers of management to control the organization is diminished. Employees have various forms of interpersonal relations among employees, such as competition, and gossip can erode the unity and continuity of organizations as well as 
negatively influence the efficiency of organizations' goals and programs (Noon \& Delbridge, 1993).

Stated differently, the positive or negative effects of gossip in organizations depend on the conditions, atmosphere, and manner of management in organizations. Common examples of organizational changes that create gossip are appointment and dismissal of directors of organizations (Gholipour, Fakheri Kozekanan, \& Zehtabi, 2011). Such changes, similar to other changes, cause untrustworthiness and hesitation in people's organizational life and have the potential to engage all employees in the process of spreading gossip. Following changes, some information of varying accuracy has been released on people, such as candidates for management positions, a dismissed manager, and people involved in the manager selection (Mills, 2010). However, such gossip can have both positive and negative functions (Rosnow \& Foster, 2005) in a way that people remove ambiguities, create a common sense, and relieve produced stress and anxiety by speaking on that area.

Despite the importance of gossip content, specific studies on the extraction of subjects and content of gossip in an organization at different levels have not been conducted. Hence, whether the content of the gossip at all levels is the same or the dimensions of gossip and their importance are subject to change as the organizational level rises remains unknown. To this end, the present study aimed to study the content of gossip and its dimensions in a reputable and reliable manner through which the tools to measure the gossip and differences in various groups and organizations with different cultures can be developed.

\section{Methodology}

\subsection{Participants}

To analyze gossip in an organizational context and to show its differences with gossip in the non-organizational environments (e.g., a school in TGQ model), participants of the study should have been selected from an organization where employees have high social interactions. The need for teamwork should also be evident in the organization and it should not merely focus on individual administrative activities to identify content and themes of gossips. For this purpose, 27 nurses, experienced hospital supervisors, and managers were selected randomly from Imam Khomeini Hospital in Ardabil from December 2019 to February 2020 to specify important involved issues from different perspectives. The selected participants were the most experienced persons in their group based on the Hospital management report. Among selected participants $44 \%$ were men, and $39 \%$ aged between $30-40,52 \%$ aged higher than 41 years.

\subsection{Interview Procedure}

Semi-structured interviews were conducted so as to facilitate a free flow of ideas with the respondents and generate information-rich data based on the clinical method of interviewing (Dapkus, 1985) to understand the meanings conveyed in communication contents between people in organizations. All participants ensured about Anonymity, Privacy, \& Confidentiality of the interviews.

One main area was covered in the interview: What do employees say about each other? The responses were allocated three subcategories:

1) People's favorite subjects in daily life (e.g., what issues would employees like most to talk about with others in their interpersonal interactions?),

2) People's conversations on others' issues in the time of organizational changes (e.g., which gossips are exchanged among employees in the shift-change time of staff and management, etc.?), and

3) The subjects of staff or conversations in the time of change in the quality of interpersonal relations (e.g., if the employees have personal disputes, how they speak about each other?).

These contents (Clegg \& van Iterson, 2009; Grosser et al., 2010) are based on a comparison with the social gossip content to present the definition of organizational gossip (limited social structure).

The interviews were conducted over the course of 10 days through tape recording and in different places at the request of the respondents. The interviews had no time limit to allow the respondents to express their opinions easily and to avoid limiting the range of topics and codes in the analyses. This strategy was adopted to obtain a wide range of possible answers. Following the interviews, data analysis was carried out in three stages. First, the transcription of the recorded voices carried out as conversation analysis method (CA). The researchers aimed at identifying the potential themes and developing a formal codebook in the first stage. In the second stage, the research team used a sample text to ensure intercoder reliability for each of the themes in the codebook. When the researchers were able to make sure that they had established acceptable and appropriate intercoder reliability levels, they moved to the final stage and applied the codebook, in a systematic form, to the entire corpus of text (Kurasaki, 2000).

Step 1: Codebook Development

In this article, the grounded theory approach (Corbin \& Strauss, 1990; Martin \& Turner, 1986) was used to detect potential themes and develop a formal codebook. The grounded theory style of qualitative research has been used extensively, from psychology to information science to education to many communities of practice within health care and to management and organization studies. Indeed, in the domain of qualitative research, the original text has assumed canonical status (Locke, 2001). 


\section{Step 2: Intercoder Reliability}

At this point, four people were trained for coding, including the two interviewers. When the team completed the code definitions, the four coders were then tasked with coding the same sample of text independently to examine the consistency of text segmentation and code application. In order to test their understanding of each code, each of the four coders read the same portions of six interviews that were selected randomly and the text was marked for all of the thirty-four code categories. The marking behaviors of the coders were compared in order to calculate the measures of coder reliability. Based on Kurasaki's work (2000), the researchers calibrated the four coders to an agreed level of .70, according to the data presented during the training phase.

The researchers also instructed each coder in order to delineate text units and assign numeric code(s) to each text unit independently. A text unit is a unit of conversation representing a single message (McFadden, Seidman, \& Rappaport, 1992), a distinguishing feature (Pennartz, 1986), or a change of subject (Dapkus, 1985).

During the open coding step, 191 open codes have been extracted. Then, regarding the similarities and differences of the codes, categorization has been done and summarized to 123 codes in 9 themes. Each themes encompasses sub-codes which totally reached to 16 concepts and 37 codebooks. Finally one theme has been deleted or combined to other themes after agreement calculation step, and resulted to eight final constructs. A sample, part of interview with one of nurses is as bellow:

.... all co-workers talk about how much others earn. But the payment details and how exactly we are measured were not clear. As colleagues say, some managers or even nurses receive more than others. I think it is different for everyone and those who have a friend among managers receive more. Mr... was after me. But he bought a new car soon, and I even heard that he wants to change his house. Does he deserve being promoted so fast? How much he earns? I am not sure about managers and supervisors' incomes, but I heard they have various advantages besides salary. So, it is not their concern how we live with such low wages. They are not worry about our problems because they earn well enough...I am not sure how I can get promoted. I have more than 10 years experiences and some of my colleagues, with less experience, are now my manger. It is clear that we should join the managers' team to get promoted. There are no obvious indexes to find a higher position and income.....

\section{Results}

We annotated the text by examining all initial six transcripts and performing the 'annotation' step. Annotations refer to the notes that are written in the margins with re- gard to the interview's contents. For the following excerpt, for instance, the title "Salary" would constitute a typical annotation: "Have you heard that the salaries of operating room staff are supposed to increase?"

A verbatim list of all of the annotations was compiled. The annotations in this list were sorted into similar categories and subcategories by the two members of the research team. The redundancies were removed and an initial hierarchy of thematic categories was created. In light of the above consolidation step, forty thematic categories were identified.

The research team developed descriptive labels for each of the forty thematic categories in order to offer the intended meaning of each category. In the next step, they operationalized them and individual reports were generated for each of the themes in order to examine the taxonomy for possible redundancies that were missed during the earlier sorting step (Kurasaki, 2000). A number of redundancies were observed and, after additional sorting, thirty-seven themes were selected for further consideration (Table 1).

The research team applied a decimal numbering system to ensure that the numerical digits represent the different levels of the themes. For example, all themes assigned with a 1.x numeric code were related to finances. The digit following the decimal further distinguishes different types of finances, in no specific order. Numeric codes assigned to individual themes are presented in Table 1 .

The codebook was further refined when training the two research assistants as coders. In the training session, the coders acquainted themselves with definitions, applications of the themes, and coding procedures (Kurasaki, 2000). At the coders' request, two amendments were made to the codebook. They unanimously chose to eliminate categories 7.2 (chances, destiny) and 7.3 (helping others' claims, the claim of advice, and solutions to others). They also decided to combine categories 7.1 and 6.4, and agreed that it better reflects its intended meaning. As a consequence of such amendments, the final codebook contained thirty-four categories and their corresponding numeric codes (Table 1).

To calculate agreement, we selected five interviews randomly. The five interviews were divided between coders who read and coded all five interviews individually. Then, to check the coders' agreement, we scored one on the parts of the interview agreed on in a group and scored zero on the parts no agreement was reached between the coders. This step can highlight the lack of compatibility and application of codes in each segment (MacQueen, McLellan, Kay, \& Milstein, 1998).

Coder agreement results of the themes are provided in Table 2. Inter-coder agreement on the thirty-four themes ranged from .69 to 1.00 with a mean of .89 . The highest agreements were on the supplemental received (1.2), financial situation (1.3), demeanor (5.1), dress (5.5), and 
Table 1: Reliability of Encoding

\begin{tabular}{|c|c|c|c|c|c|}
\hline Theme List & $\begin{array}{l}\text { Numeric } \\
\text { code }\end{array}$ & Agreement & Theme List & $\begin{array}{l}\text { Numeric } \\
\text { code }\end{array}$ & Agreement \\
\hline Salary & 1.1 & 0.99 & Personality & 5.3 & 0.96 \\
\hline Supplemental receive & 1.2 & 1.00 & Morality & 5.4 & 0.85 \\
\hline Financial situation & 1.3 & 1.00 & Clothes & 5.5 & 1.00 \\
\hline Economic activities & 1.4 & 0.98 & Personal appearance & 5.6 & 1.00 \\
\hline Appointment and promotion & 2.1 & 0.95 & influence & 6.1 & 0.82 \\
\hline Job displacements & 2.2 & 0.87 & Relations & 6.2 & 0.78 \\
\hline Persons' brand & 2.3 & 0.90 & Association with power bases & 6.3 & 0.83 \\
\hline Punishment and leaving jobs & 2.4 & 0.79 & Political Relations & 6.4 & 0.88 \\
\hline Education & 3.1 & 0.98 & Combined with 6.4 & 7.1 & - \\
\hline Backgrounds & 3.2 & 0.97 & Deleted & 7.2 & - \\
\hline Capabilities & 3.3 & 0.69 & Deleted & 7.3 & - \\
\hline Achievements & 4.1 & 0.88 & Familial Culture & 8.1 & 0.82 \\
\hline The effort & 4.2 & 0.94 & Aspects of life & 8.2 & 0.87 \\
\hline Empowerment & 4.3 & 0.80 & Ethical issues & 8.3 & 0.98 \\
\hline Performance & 4.4 & 0.84 & Family matters & 8.4 & 0.85 \\
\hline Illegal activities & 4.5 & 0.92 & Security and comfort & 9.1 & 0.86 \\
\hline Failure & 4.6 & 0.85 & Difficulty work & 9.2 & 0.88 \\
\hline Demeanor & 5.1 & 1.00 & Business issues & 9.3 & 0.90 \\
\hline Motivation & 5.2 & 0.78 & & & \\
\hline
\end{tabular}

Table 2: Descriptive labels of Constructs and Codes

\begin{tabular}{|c|c|c|c|}
\hline Construct & Code & Construct & Code \\
\hline \multirow{4}{*}{ Finance } & Salary & \multirow{4}{*}{$\begin{array}{l}\text { Persons' commu- } \\
\text { nications }\end{array}$} & Influence \\
\hline & Supplemental receive & & Relations \\
\hline & Financial situation & & Association with power bases \\
\hline & Economic activities & & Political Relations \\
\hline \multirow{4}{*}{$\begin{array}{l}\text { Persons' } \\
\text { Positions }\end{array}$} & Appointment and promotion & \multirow{4}{*}{$\begin{array}{l}\text { Confidentiality } \\
\text { issues }\end{array}$} & Familial Culture \\
\hline & Job displacements & & Aspects of life \\
\hline & Persons' brand & & Ethical issues \\
\hline & Punishment and leaving jobs & & Family matters \\
\hline \multirow{3}{*}{$\begin{array}{l}\text { Persons' } \\
\text { Biography }\end{array}$} & Education & \multirow{3}{*}{ Job conditions } & Security and comfort \\
\hline & backgrounds & & Difficulty work \\
\hline & Capabilities & & Business issues \\
\hline \multirow{6}{*}{ Merit } & Achievements & \multirow{6}{*}{$\begin{array}{l}\text { Personal characte- } \\
\text { ristics }\end{array}$} & Demeanor \\
\hline & The effort & & Motivation \\
\hline & Empowerment & & Personality \\
\hline & Performance & & Morality \\
\hline & Illegal activities & & Clothes \\
\hline & Failure & & Personal appearance \\
\hline
\end{tabular}


Table 3: Frequency and Prioritization of Groups Codes

\begin{tabular}{|c|c|c|c|c|c|c|c|c|}
\hline \multirow{2}{*}{$\frac{\text { Groups }}{\text { Groups codes }}$} & \multicolumn{2}{|c|}{ Managers } & \multicolumn{2}{|c|}{ Supervisors } & \multicolumn{2}{|c|}{ Nurses } & \multirow[b]{2}{*}{ Total $\mathbf{F}$} & \multirow[b]{2}{*}{$\mathbf{P}$} \\
\hline & $\mathbf{F}$ & $\mathbf{P}$ & $\mathbf{F}$ & $\mathbf{P}$ & $\mathbf{F}$ & $\mathbf{P}$ & & \\
\hline Salary & 6 & 2.8 & 9 & 4.2 & 15 & 8.1 & 30 & 4.9 \\
\hline Supplemental receive & 3 & 1.4 & 13 & 6.1 & 25 & 13.5 & 41 & 6.7 \\
\hline Financial situation & 8 & 3.8 & 6 & 2.8 & 11 & 5.9 & 25 & 4.1 \\
\hline Economic activities & 5 & 2.4 & 2 & 0.9 & 0 & 0 & 7 & 1.6 \\
\hline Appointment and promotion & 14 & 6.73 & 8 & 3.8 & 5 & 2.7 & 27 & 4.4 \\
\hline Job displacements & 5 & 2.4 & 8 & 3.8 & 6 & 3.2 & 19 & 3.5 \\
\hline Persons' brand & 2 & 0.9 & 3 & 1.4 & 3 & 1.6 & 8 & 1.3 \\
\hline Punishment and leaving jobs & 0 & 0 & 6 & 2.9 & 2 & 1.1 & 8 & 1.3 \\
\hline Education & 6 & 2.8 & 4 & 1.9 & 1 & 0.5 & 11 & 1.8 \\
\hline Backgrounds & 10 & 4.8 & 4 & 1.9 & 2 & 1.1 & 16 & 2.6 \\
\hline Capabilities & 4 & 1.9 & 4 & 1.9 & 0 & 0 & 8 & 1.3 \\
\hline Achievements & 7 & 3.3 & 5 & 2.4 & 0 & 0 & 12 & 1.9 \\
\hline The effort & 4 & 1.9 & 5 & 2.4 & 8 & 4.3 & 17 & 2.8 \\
\hline Empowerment & 27 & 12.9 & 12 & 5.7 & 14 & 7.6 & 53 & 8.7 \\
\hline Performance & 17 & 8.1 & 23 & 11 & 9 & 4.9 & 49 & 8.1 \\
\hline Illegal activities & 7 & 3.3 & 4 & 2 & 0 & 0 & 11 & 1.8 \\
\hline Failure & 7 & 3.3 & 10 & 4.8 & 5 & 2.7 & 22 & 3.6 \\
\hline Demeanor & 5 & 2.4 & 7 & 3.3 & 6 & 3.2 & 18 & 2.9 \\
\hline Motivation & 8 & 3.8 & 2 & 1 & 5 & 2.7 & 15 & 2.4 \\
\hline Personality & 6 & 2.9 & 13 & 6.2 & 15 & 8.1 & 34 & 5.6 \\
\hline Morality & 3 & 1.4 & 7 & 3.3 & 3 & 1.6 & 13 & 2.1 \\
\hline Clothes & 2 & 1 & 5 & 2.4 & 3 & 0 & 7 & 1.2 \\
\hline Personal appearance & 0 & 0 & 2 & 0.9 & 0 & 0 & 2 & 0.3 \\
\hline Influence & 4 & 1.9 & 0 & 0 & 3 & 1.6 & 7 & 1.2 \\
\hline Relations & 2 & 1 & 2 & 0.9 & 6 & 3.2 & 10 & 1.6 \\
\hline Association with power bases & 9 & 4.3 & 8 & 3.8 & 8 & 4.3 & 25 & 4.1 \\
\hline Political Relations & 8 & 3.8 & 1 & 0.5 & 3 & 1.6 & 12 & 2.0 \\
\hline Familial Culture & 4 & 1.9 & 3 & 1.4 & 1 & 0.5 & 8 & 1.3 \\
\hline Aspects of life & 6 & 2.9 & 9 & 4.3 & 5 & 2.7 & 20 & 3.3 \\
\hline Ethical issues & 3 & 1.4 & 3 & 1.4 & 3 & 1.6 & 9 & 1.5 \\
\hline Family matters & 10 & 4.8 & 7 & 3.3 & 7 & 3.8 & 24 & 4.0 \\
\hline Security and comfort & 0 & 0 & 2 & 0.9 & 2 & 1.1 & 4 & 0.7 \\
\hline Difficulty work & 2 & 1 & 6 & 2.9 & 6 & 3.2 & 14 & 2.3 \\
\hline Business issues & 4 & 1.9 & 7 & 3.3 & 6 & 3.2 & 17 & 2.8 \\
\hline Total & 208 & 100 & 210 & 100 & 185 & 100 & 603 & 100 \\
\hline
\end{tabular}

$\mathrm{F}=$ Frequency, $\mathrm{P}=$ Percent of Answers for Each Group 
personal appearance (5.6). The lowest agreement was on capabilities (3.3). These results are summarized in Table 1. Data

Step 3: Applying the Codebook Systematically to the

Descriptive labels were developed in order to display the intended meaning of codes as shown in the Table 2, perform thematic searches of all data, and count the number of occurrences for each one of the eight constructs. We calculated the frequency of thematic categories as an indication of the prominence of each thematic code (Table 3).

To investigate the importance of issues for staff, the frequency and average of the codes and constructs were calculated based on which the constructs were prioritized. Table 3 shows the frequency and average for each code with separated groups of employees.

As Table 3 shows, the highest frequencies in each of the three groups are different. For managers' empower- ment $(\mathrm{F}=27)$, performance $(\mathrm{F}=17)$ and appointment and promotions $(\mathrm{F}=14)$ were the most frequent contents of gossip respectively. Among supervisors, however, performance got the highest rank with 23 frequencies and was followed by speak about personality and supplementary whose frequency was13. Among nurses the topics frequencies were much different with supplemental receiving the first rank $(\mathrm{F}=25)$, personality the second rank $(\mathrm{F}=15)$ and empowerment the third rank $(\mathrm{F}=14)$.

Table 4 shows the frequency, frequency percentage, and average of constructs. As represented in Table 5, the construct of "merit" with total weighted average of 5.85, and frequency percentage of 27.52, was the first priority among the answers and Persons' biography with an average of 1.18 and 5.57 frequency percentage was the last priority (Table 4).

Table 4: Frequency and Prioritization of Construct

\begin{tabular}{|c|c|c|c|c|c|c|c|c|c|}
\hline & $\begin{array}{l}\text { Merit } \\
(R=1)\end{array}$ & $\begin{array}{c}\text { Finance } \\
(R=2)\end{array}$ & $\begin{array}{c}\text { personal } \\
\text { character- } \\
\text { istics } \\
(R=3)\end{array}$ & $\begin{array}{l}\text { Confidentiali- } \\
\text { ty issues } \\
(R=4)\end{array}$ & $\begin{array}{c}\text { Persons' } \\
\text { Positions } \\
\quad(R=5)\end{array}$ & $\begin{array}{c}\text { persons' } \\
\text { Communica- } \\
\text { tions } \\
(\mathrm{R}=6)\end{array}$ & $\begin{array}{l}\text { Job con- } \\
\text { ditions } \\
(R=7)\end{array}$ & $\begin{array}{c}\text { Persons' } \\
\text { Biography } \\
(\mathrm{R}=8)\end{array}$ & Total \\
\hline $\begin{array}{l}\text { Total frequen- } \\
\text { cy }\end{array}$ & 158 & 92 & 87 & 61 & 55 & 54 & 35 & 32 & 603 \\
\hline Percent & 27.52 & 16.02 & 15.15 & 10.62 & 9.58 & 9.40 & 6.09 & 5.57 & 100 \\
\hline $\begin{array}{l}\text { Average of } \\
\text { managers }\end{array}$ & 9.00 & 2.58 & 3.14 & 3.28 & 2.57 & 3.28 & 0.85 & 2.42 & -- \\
\hline $\begin{array}{l}\text { Average of } \\
\text { supervisors }\end{array}$ & 5.90 & 2.60 & 3.60 & 2.20 & 2.40 & 1.10 & 1.50 & 1.20 & -- \\
\hline $\begin{array}{l}\text { Average of } \\
\text { nurses }\end{array}$ & 3.60 & 4.80 & 2.90 & 1.60 & 1.30 & 2.00 & 1.40 & 0.30 & -- \\
\hline Total average & 5.85 & 3.40 & 3.22 & 2.25 & 2.03 & 2.00 & 1.29 & 1.18 & -- \\
\hline
\end{tabular}

$\mathrm{R}=$ Rank based on average score

In executives' group, punishment code and personal appearance were not presented in the answers and thus has zero repetition score. Empowerment is the most repeated theme. Among the group of supervisors, the code was not mentioned in the replies and the most frequent repetition was code performance. Among the nurses, the highest frequency $(\mathrm{F}=24)$ was related to supplementary received and the lowest frequency $(\mathrm{F}=0)$ was related to economic activities, capabilities, achievements, clothes, personal appearance, and illegal activities.

The difference test shows the average difference of answers among three groups of samples. Meaningfulness of a code's differences indicates that the corresponding code does not have the same importance in the viewpoints of all three groups, and could represent a potential difference among the respondents.
Analysis of variance among the eight constructs shows agreement/disagreement among respondents' comments on the defined codes, which suggests gossips in organizations, from the perspective of supervisors, nurses, and managers, are identical in some areas but differ in other areas. The difference between tasks, types of works and individuals' responsibilities at different organizational levels makes some factors significant for the staff to discuss among themselves. According to these three groups, oneway ANOVA test was applied to each variable. The tests for normality and homogeneity were done for these groups and the results verified for the ANOVA analysis. Table 5 shows the results of one-way ANOVA along with Leven test results for each constructs.

According to the coefficient of analysis of variance for constructs of personal characteristics (0.78) and job con- 
Table 5: Results of ANOVA between constructs

\begin{tabular}{|c|c|c|c|c|c|c|}
\hline & & SS & $d f$ & MS & $\mathrm{F}$ & Sig. \\
\hline \multirow[t]{2}{*}{ Merit } & Between Groups & 120.107 & 2 & 60.054 & 26.063 & .000 \\
\hline & Within Groups & 55.300 & 24 & 2.304 & & \\
\hline (Levene $=.926 ;$ Sig. $=.410$ ) & Total & 175.407 & 26 & & & \\
\hline \multirow[t]{2}{*}{ Finance } & Between Groups & 30.804 & 2 & 15.402 & 17.023 & .000 \\
\hline & Within Groups & 21.714 & 24 & .905 & & \\
\hline$($ Levene $=.247 ;$ Sig. $=.783)$ & Total & 52.519 & 26 & & & \\
\hline \multirow[t]{3}{*}{ Personal characteristics } & Between Groups & 2.510 & 2 & 1.255 & .789 & .466 \\
\hline & Within Groups & 38.157 & 24 & 1.590 & & \\
\hline & Total & 40.667 & 26 & & & \\
\hline \multirow[t]{2}{*}{ Confidentiality Issues } & Between Groups & 11.757 & 2 & 5.878 & 5.144 & .014 \\
\hline & Within Groups & 27.429 & 24 & 1.143 & & \\
\hline$($ Levene= .027; Sig. $=.974)$ & Total & 39.185 & 26 & & & \\
\hline \multirow[t]{2}{*}{ Persons' Positions } & Between Groups & 8.749 & 2 & 4.374 & 4.005 & .032 \\
\hline & Within Groups & 26.214 & 24 & 1.092 & & \\
\hline$($ Levene $=1.187 ;$ Sig. $=.323)$ & Total & 34.963 & 26 & & & \\
\hline \multirow[t]{2}{*}{ Persons' Communications } & Between Groups & 19.671 & 2 & 9.836 & 22.855 & .000 \\
\hline & Within Groups & 10.329 & 24 & .430 & & \\
\hline$($ Levene $=.304 ;$ Sig. $=.740)$ & Total & 30.000 & 26 & & & \\
\hline \multirow[t]{2}{*}{ Job conditions } & Between Groups & 1.872 & 2 & .936 & 1.265 & .300 \\
\hline & Within Groups & 17.757 & 24 & .740 & & \\
\hline$($ Levene $=.622 ;$ Sig. $=.545)$ & Total & 19.630 & 26 & & & \\
\hline \multirow[t]{2}{*}{ Persons' Biography } & Between Groups & 18.660 & 2 & 9.330 & 10.456 & .001 \\
\hline & Within Groups & 21.414 & 24 & .892 & & \\
\hline$($ Levene= 2.143; Sig. $=.139)$ & Total & 40.074 & 26 & & & \\
\hline
\end{tabular}

$\mathrm{SS}=$ the sum of squares, $\mathrm{DF}=$ the degrees of freedom, $\mathrm{MS}=$ the mean sum of squares, $\mathrm{F}=$ the F-statistic, Sig. $=$ the P-value.

ditions (1.26), which are not at significant levels, no difference was observed among the different groups on these constructs. The variance coefficients of constructs of merit (26.06), finance (17.02), confidentiality issues (5.14), persons' positions (4.0) persons' communications (22.85), and persons' biography (10:45) were significant, thereby suggesting the topics of organizational gossip have different importance among different groups, and organizational staff do not necessarily use common themes in gossiping.

According to these variables, due to the differences are statistically significant, post hoc analysis should be carried out for the reason behind the significant result. The results for Tukey's HSD test is shown in the Table 6.

For each height differences between points (Table 6), sub groups were shown in pairwise comparison. The results showed that all three groups are significantly different in Merit, and Persons' communications. Whereas gossiping about personal characteristics, and job conditions include all three groups in one subset. Therefore, there are no differences between these three groups regards to gossiping contents about personal characteristics and job conditions. Interestingly, nurses and supervisors are same subset in finance and persons' biography and in both constructs managers stands alone in one separate subset. However, supervisors showed similarities with nurses and managers in constructs of persons' positions, and confidentiality issues.

\section{Discussion and Conclusion}

The first aim of this study was to identify gossiping contents in hospitals where employees are under huge work pressure and stress, especially during this Covid-19 period. The second aim of the study was to explore gossiping differences at organizational levels to show that employees at the various levels of a hospital, as an example of organization, do gossip significantly and the topics of their 
Table 6: Post-Hoc analysis results for groups

\begin{tabular}{|c|c|c|c|c|c|c|c|c|c|c|c|}
\hline \multicolumn{4}{|l|}{ Merit } & \multicolumn{4}{|l|}{ Finance } & \multicolumn{4}{|c|}{ Personal characteristics } \\
\hline & \multicolumn{3}{|c|}{ Subset } & & \multicolumn{3}{|c|}{ Subset } & & \multicolumn{3}{|c|}{ Subset } \\
\hline & 1 & 2 & 3 & & 1 & 2 & 3 & & 1 & 2 & 3 \\
\hline Managers & 3.600 & & & Nurses & 2.571 & & & Managers & 2.900 & & \\
\hline Supervisors & & 5.900 & & Supervisors & 2.600 & & & Nurses & 3.142 & & \\
\hline Nurses & & & 9.000 & Managers & & & 4.800 & Supervisors & 3.600 & & \\
\hline \multicolumn{4}{|c|}{ Confidentiality Issues } & \multicolumn{4}{|c|}{ Persons' Positions } & \multicolumn{4}{|c|}{ Persons' Communications } \\
\hline & \multicolumn{3}{|c|}{ Subset } & & \multicolumn{3}{|c|}{ Subset } & & \multicolumn{3}{|c|}{ Subset } \\
\hline & 1 & 2 & 3 & & 1 & 2 & 3 & & 1 & 2 & 3 \\
\hline Managers & 1.600 & & & Managers & 1.300 & & & Supervisors & 1.100 & & \\
\hline Supervisors & 2.200 & 2.200 & & Supervisors & 2.400 & 2.400 & & Managers & & 2.00 & \\
\hline Nurses & & 3.285 & & Nurses & & 2.571 & & Nurses & & & 3.285 \\
\hline \multicolumn{4}{|c|}{ Job conditions } & \multicolumn{4}{|c|}{ Persons' Biography } & & & & \\
\hline & \multicolumn{3}{|c|}{ Subset } & & \multicolumn{3}{|c|}{ Subset } & & & & \\
\hline & 1 & 2 & 3 & & 1 & 2 & 3 & & & & \\
\hline Nurses & .857 & & & Managers & .300 & & & & & & \\
\hline Managers & 1.400 & & & Supervisors & 1.200 & & & & & & \\
\hline Supervisors & 1.500 & & & Nurses & & $2.42 \varepsilon$ & & & & & \\
\hline
\end{tabular}

Tukey HSDa (subset for alpha $=0.05$ );

Means for groups in homogeneous subsets are displayed. Sig. $=$ The P-value

gossips vary. The third goal was to categorize the contents of gossip in hospitals.

The results showed that the content of gossips in hospitals has some differences with the content of gossips in a social structure (Nevo et al., 1993) and is in line with the results of (Foster, 2004). This means that the context of the work provides or affects the content of gossip. Also, the aims of gossiping in hospitals are far different from the aims of gossiping in social environments. It was shown that the merit and financial issues got the first and second highest ranks between other constructs, respectively. Therefore, we can conclude that gossiping contents are various based on social or organizational milieu.

The second result of this study indicates that employees at organizational levels have different aims for gossiping. In line with Durmuş et al. (2020), we also found differences between employees at different levels of hospitals. These diversities may be rooted in the work attitudes and behaviors which are affected by work and need to adjustment. At the managerial levels, it may be for accessing relevant information in their decision-making (Liff \& Wikström, 2021). But at the lower levels in hospitals, work stress and responsibility pressure make a stronger demand for group protection, coping strategies, and reducing stress. These findings are in contradiction to Wu, Birtch, Chiang, and Zhang (2018) findings. On the one hand, the themes of gossip, at the practical level of a hospital, are mostly individual oriented while on the other, at the higher level of a hospital, contents tend to be organizationally oriented and includes issues such as performance. More to the point is that, the employees may use gossiping in response to their superiors' misbehaviors and to put them under pressure (Ye et al., 2021). This response helps them feel better and cope with situation, or acts as the conjunction between these levels (Michelson et al., 2010). Additionally, a transition in the organizational level (from nurses to managers) shows that the discussion topics on gossips shift from individual issues such as financial matters and receiving side benefits to human characteristics, such as performance and character leading to organizational issues including empowerment. This diversity may be rooted in the concerns in the hospital or due to the different situations of each group that affects their motivations for gossiping (Dores Cruz, Beersma, Dijkstra, \& Bechtoldt, 2019). Nurses have the same concerns about the financial issues. Thus, the strategy for coping motivates them to speak about shared needs and situations. The same conclusion is generalizable for supervisors and managers. Their situations are varying, too.

However, the rules would provide a context for the growth of gossiping. Some official rules and regulations in organizations make differences more pronounced e.g., laws and regulations on uniforms (Lee \& Workman, 2013).

The results also showed that gossip topics can be divided into eight groups involving main issues and their sub-codes involving 34 more minor issues. The main top- 
ics of gossip include confidentiality issues, merits, financial issues, personal characteristics, individuals' positions, individuals' communications, individuals' biography, and job conditions.

The category of merits and financial affairs are the first two priorities that hospital personnel talk about. Personnel always seek to compare the ability and competence of others with their own abilities and competence and thereby make comparisons about revenues and supplements received from organizations or outside sources.

However, among managers and supervisors, merit is the first priority in comparison with other issues of gossip. This is while, among nurses, financial issues are of greatest importance. Compared with head nurses and hospital administrators, staff nurses do not benefit from suitable payments. Likewise, no acceptable payment transparency exists among nurses, making them attempt to spread gossip while their superiors mainly try to advance and succeed in their positions.

Furthermore, the analysis of the results between groups showed that however all three groups have similarities about gossiping, but the as person's position changed to managerial levels in the hospital, the gossiping constructs are going to more related to the job conditions. Also, people in organization have same gossip constructs based on their job situation. For example, all staff in all levels do gossip about job conditions. Therefore, the employee tries to find same issues for gossiping which means that even the positions in the organizations are in close relation with colleagues' concern.

Identifying the quality of relationships among members of organizations and gossiping activities can be a tool for managers to understand and better manage the conditions of their organizations and human resources.

\subsection{Implications for Managers}

Managers should know that the consequences of gossip can be both positive and negative (Michelson \& Mouly, 2002), but its main function is to provide information related to the organization. The employees in an organization are likely to use gossip in response to organizational situations. Because of this, the contents of the gossip are different at different organizational levels. It can also be argued that within an organization, topics can be of varying importance based on job levels and hierarchies, such that the average frequency groups differ in all constructs except for private issues and personal characteristics.

The authors hope this study contributes to improving knowledge in the field of gossip and in examining the impact of organizational variables regarding the content of gossip. It is also hoped that managers take benefit of gossip to reduce organizational resistance to change through sharing information. The results of the study may be of practical use for checking organizational variables and situations. The contents of the gossips would be helpful to find employees' concerns and viewpoints, even about appointments and evaluating the performance of the hospitals.

Limitations of this study, such as the number of people participating in the research and the qualitative method used should be considered in future studies. Also, due to the pandemic of Covid-19, employees in the hospitals are under a huge workload and stress, and therefore, the results may be different in normal time.

Future studies on different organizations are recommended. In particular, checking the gossip in virtual spaces and in different communities can contribute significantly to better identify the communication issues in virtual organizations and the formation of gossip in them. We also suggest studying employee roles in gossiping and their personality in and out of the job.

\section{Literature}

Aambø, A. (2017). Gossip and rumors-undervalued sources of suffering and disease. European Journal of Public Health, 27(suppl_3). https://doi.org/10.1093/eurpub/ckx189.063

Abdi, M., Chaib, R., \& Verzea, I. (2020). Contribution to the Assessment of the Quality of Life at Work: a Case Study. Behavior Studies in Organizations, 4, 27-37. https://doi.org/10.32038/JBSO.2020.04.03

Ardabili, F. S. (2020). Moderating-mediating Effects of Leader Member Exchange, Self-efficacy and Psychological Empowerment on Work Outcomes among Nurses. Organizacija, 53(3), 246-258. https://doi. org/10.2478/orga-2020-0016

Arfara, C., Tsivos, G., Samanta, I., \& Kyriazopoulos, P. (2017). The Integration of Information Technology to Facilitate HRM Functions: The Case of the Health Care Sector (Biomedicine Group). Management and Business Research Quarterly, 3, 27-38. https://doi. org $/ 10.32038 / \mathrm{mbrq} .2017 .03 .03$

Babaei Aghbolagh, M., \& Ardabili, F. S. (2016). An overview of the social functions of gossip in the hospitals. Management Issues in Healthcare System, 2(1), 27-33. https://doi.org/10.33844/mihs.2016.60194

Bechtoldt, M. N., Beersma, B., \& Dijkstra, M. T. M. (2020). Editorial: Why People Gossip and What It Brings About: Motives for, and Consequences of Informal Evaluative Information Exchange. Frontiers in Psychology, 11(24). https://doi.org/10.3389/ fpsyg.2020.00024

Beersma, B., \& Van Kleef, G. A. (2011). How the grapevine keeps you in line: Gossip increases contributions to the group. Social Psychological and Personality Science, 2(6), 642-649. https://doi. org/10.1177/1948550611405073. 
Beersma, B., \& Van Kleef, G. A. (2012). Why people gossip: An empirical analysis of social motives, antecedents, and consequences. Journal of Applied Social Psychology, 42(11), 2640-2670. https://doi.org/10.1111/j.1559-1816.2012.00956.x

Bulduk, S., Özel, İ., \& Dinçer, Y. (2016). Informal communication in healthcare (gossip and rumour): nurses' attitudes. Athens Journal of Health, 3(4), 23-29. https://doi.org/10.30958/ajh.3-4-3

Ceylan, S. S., \& Çetinkaya, B. (2020). Attitudes towards gossip and patient privacy among paediatric nurses. Nursing Ethics, 27(1), 289-300. https://doi. org/10.1177/0969733019845124.

Chang, K., \& Kuo, C.-C. (2020). Can subordinates benefit from Manager's gossip? European Management Journal. https://doi.org/10.1016/j.emj.2020.09.009

Clegg, S. R., \& van Iterson, A. (2009). Dishing the dirt: gossiping in organizations. Culture and Organization, 15(3-4), 275-289. https://doi. org/10.1080/14759550903119293

Corbin, J. M., \& Strauss, A. (1990). Grounded theory research: Procedures, canons, and evaluative criteria. Qualitative Sociology, 13(1), 3-21. https://doi.org/10.1007/ BF00988593

Dapkus, M. A. (1985). A thematic analysis of the experience of time. Journal of Personality and Social Psychology, 49(2), 408. https://doi.org/10.1037/00223514.49.2.408

Dores Cruz, T. D., Beersma, B., Dijkstra, M. T. M., \& Bechtoldt, M. N. (2019). The Bright and Dark Side of Gossip for Cooperation in Groups. Frontiers in Psychology, 10(1374). https://doi.org/10.3389/ fpsyg.2019.01374

Dores Cruz, T. D., Nieper, A. S., Testori, M., Martinescu, E., \& Beersma, B. (2021). An Integrative Definition and Framework to Study Gossip. Group \& Organization Management, 46(2), 252-285.

https://doi,org/10.1177/1059601121992887

Durmuş, A., Kirilmaz, H., \& Şahin, Ö. (2020). Is Gossip Associated with Nurses' Job Performance Perceptions? Eskişehir Osmangazi Üniversitesi İktisadi ve İdari Bilimler Dergisi, 15(1), 17-30. https://doi.org/10.17153/ oguiibf.520390.

Eckhaus, E., \& Ben-Hador, B. (2020). Gossip and Pro Social Behavior, Cham.

Ellwardt, L., Labianca, G., \& Wittek, R. (2012). Who are the objects of positive and negative gossip at work?: A social network perspective on workplace gossip. Social Networks, 34(2), 193-205. https://dx.doi.org/10.1016/j.socnet.2011.11.003

Fan, Z., \& Dawson, P. (2021). Gossip as evaluative sensemaking and the concealment of confidential gossip in the everyday life of organizations. Management Learning, $\quad 0(0), \quad 1350507620979366 . \quad$ https://doi. org/10.1177/1350507620979366
Foster, E. K. (2004). Research on gossip: Taxonomy, methods, and future directions. Review of General Psychology, 8(2), 78. https://doi.org/10.1037/10892680.8.2.78

Georganta, K., Panagopoulou, E., \& Montgomery, A. (2014). Talking behind their backs: Negative gossip and burnout in Hospitals. Burnout Research, 1(2), 7681. https://doi.org/10.1016/j.burn.2014.07.003

Gholipour, A., Fakheri Kozekanan, S., \& Zehtabi, M. (2011). Utilizing gossip as a strategy to construct organizational reality. Business Strategy Series, 12(2), 5662. https://doi.org/10.1108/17515631111114859

Grosser, T. J., Kidwell, V. L., \& Labianca, G. J. (2012). Hearing it through the grapevine: Positive and negative workplace gossip. Organizational Dynamics, 41, 52-61. https://doi.org/10.1016/j.orgdyn.2011.12.007

Grosser, T. J., Lopez-Kidwell, V., \& Labianca, G. (2010). A social network analysis of positive and negative gossip in organizational life. Group \& Organization Management, 35(2), 177-212. https://doi. org/10.1177/1059601109360391

Hallett, T., Harger, B., \& Eder, D. (2009). Gossip at work: Unsanctioned evaluative talk in formal school meetings. Journal of Contemporary Ethnography, 38(5), 584618. https://doi.org/10.1177/0891241609342117

Kim, A., Moon, J., \& Shin, J. (2019). Justice perceptions, perceived insider status, and gossip at work: A social exchange perspective. Journal of Business Research, 97, 30-42. https://doi.org/10.1016/j.jbusres.2018.12.038

Kniffin, K. M., \& Wilson, D. S. (2005). Utilities of gossip across organizational levels. Human Nature, 16(3), 278-292. https://doi.org/10.1007/s12110-005-1011-6

Kniffin, K. M., \& Wilson, D. S. (2010). Evolutionary perspectives on workplace gossip: Why and how gossip can serve groups. Group \& Organization Management. 35(2), 150-176. https://doi. org $/ 10.1177 / 1059601109360390$

Kurasaki, K. S. (2000). Intercoder reliability for validating conclusions drawn from open-ended interview data. Field Methods, 12(3), 179-194. https://doi.or$\mathrm{g} / 10.1177 / 1525822 \mathrm{X} 0001200301$

Lee, S.-H., \& Workman, J. E. (2013). Gossip, self-monitoring, and fashion consumer groups. Clothing and Textiles Research Journal, 31(2), 67-80. https://doi. org/10.1177/0887302X13481262

Liff, R., \& Wikström, E. (2021). Rumours and gossip demand continuous action by managers in daily working life. Culture and Organization, 1-20. https://doi.org/10 $.1080 / 14759551.2021 .1884681$

Liu, T., Wu, L., Yang, Y., \& Jia, Y. (2020). Work-to-Family Spillover Effects of Workplace Negative Gossip: A Mediated Moderation Model. Frontiers in Psychology, 11, 1612. https://doi.org/10.3389/fpsyg.2020.01612

Locke, K. (2001). Grounded Theory in Management Re- 
search: Sage.

Martin, P. Y., \& Turner, B. A. (1986). Grounded theory and organizational research. The Journal of Applied Behavioral Science, 22(2), 141-157. https://doi. org/10.1177/002188638602200207

McFadden, L., Seidman, E., \& Rappaport, J. (1992). A comparison of espoused theories of self-and mutual help: Implications for mental health professionals. Professional Psychology: Research and Practice, 23(6), 515. https://psycnet.apa.org/buy/1993-14766-001

Michelson, G., \& Mouly, V. S. (2002). 'You Didn't Hear it From Us But...': Towards an Understanding of Rumour and Gossip in Organisations. Australian Journal of Management, 27(1 suppl), 57-65.

https://doi.org/10.1177/031289620202701S07

Michelson, G., Van Iterson, A., \& Waddington, K. (2010). Gossip in organizations: Contexts, consequences, and controversies. Group \& Organization Management, 35(4), 371-390. https://doi. org/10.1177/1059601109360389

Mills, C. (2010). Experiencing gossip: The foundations for a theory of embedded organizational gossip. Group \& Organization Management, 35(2), 213-240. https:// doi.org/10.1177/1059601109360392

Nevo, O., Nevo, B., \& Derech-Zehavi, A. (1993). The development of the tendency to gossip questionnaire: Construct and concurrent validation for a sample of Israeli college students. Educational and Psychological Measurement, 53(4), 973-981. https://doi.org/10.1177/ 0013164493053004010.

Noon, M., \& Delbridge, R. (1993). News from behind my hand: Gossip in organizations. Organization studies, 14(1), 23-36. https://doi.org/10.1177/0170840693014 00103.

Pennartz, P. J. (1986). Atmosphere at home: A qualitative approach. Journal of Environmental Psychology, 6(2), 135-153. https://doi.org/10.1016/S02724944(86)80014-7.

Rosnow, R. L., \& Foster, E. K. (2005). Rumor and gossip research. Psychological Science Agenda, 19(4). http:// www.apa.org/science/about/psa/2005/04/gossip

Şantaş, G., Uğurluoğlu, Ö., Özer, Ö., \& Demir, A. (2018). Do gossip functions effect on organizational revenge and job stress among health personnel? Journal of Health Management, 20(1), 64-72. https://doi. org/10.1177/0972063417747724

Tan, N., Yam, K. C., Zhang, P., \& Brown, D. J. (2021). Are You Gossiping About Me? The Costs and Benefits of High Workplace Gossip Prevalence. Journal of Business and Psychology, 36(3), 417-434. https://doi. org/10.1007/s10869-020-09683-7

Thomas, S. A., \& Rozell, E. J. (2007). Gossip and nurses: malady or remedy? The Health Care Manager, 26(2), 111-115. https://doi.org/ 10.1097/01.
HCM.0000268613.02997.8c

Waddington, K. (2005). Behind closed doors-the role of gossip in the emotional labour of nursing work. International Journal of Work Organisation and Emotion, 1(1), 35-47. https://doi.org/10.1504/IJWOE.2005.007325

Waddington, K., \& Michelson, G. (2007). Analysing gossip to reveal and understand power relationships, political action and reaction to change inside organisations. Paper presented at the CMS conference - 2007. http://wms.ac. nz/ejrot/cmsconference/2007/proceedings/talkpowerandorganisation al/waddington. pdf.

Wittek, R., Hangyi, H., Van Duijn, M., \& Carroll, C. (2000). Social capital, third party gossip, and cooperation in organizations. The Management of Durable Relations: Theoretical Models and Empirical Studies of Households and Organizations, Edited by Jeroen Weesie and Werner Raub, Amsterdam, ThelaThesis. https://ssrn.com/abstract=2655664

Wu, L.-Z., Birtch, T. A., Chiang, F. F. T., \& Zhang, H. (2018). Perceptions of Negative Workplace Gossip: A Self-Consistency Theory Framework. Journal of Management, 44(5), 1873-1898. https://doi. org $/ 10.1177 / 0149206316632057$

Ybema, S. (2004). Managerial postalgia: Projecting a golden future. Journal of Managerial Psychology, 19(8), 825-841. https://doi.org/10.1108/02683940410568284

Ye, C., He, B., \& Sun, X. (2021). Subordinates' negative workplace gossip leads to supervisor abuse: based on the conservation of resources theory. Chinese Management Studies, ahead-of-print(ahead-of-print). https:// doi.org/10.1108/CMS-09-2020-0387

Maryam Babaei Aghbolagh holds an MSc in Management and is a lecturer at the Department of Management, Islamic Azad University, Ardabil Branch, Ardabil, Iran. Her research focuses on organizational behavior, organizational psychology and leadership.

Farzad Sattari Ardabili is Assistant Professor at the Department of Management, Islamic Azad University, Ardabil Branch, Ardabil, Iran. His research focuses on leadershirp and organizational behavior, especially on managerial wisdom, career adaptability, ambidextrous behavior, and self-efficacy.

Elena Voitenko is PhD in Psychology and is an Associate Professor at the Department of Psychology, Kyiv National University of Trade and Economics, Ukraine. Her research interests include: professional well-being, organizational psychology, professional maladjustment and emotional burnout. 